\title{
Antiphospholipid antibodies in patients with upper-extremity deep vein thrombosis
}

\author{
MILENA K. NIKOLOVA-VLAHOVA ${ }^{l}$, KRASIMIR V. NIKOLOV ${ }^{l}$, MARTA P. BALEVA ${ }^{l}$, \\ ALEXEY S. SAVOV
}

${ }^{1}$ University Hospital Alexandrovska, Sofia, Bulgaria

${ }^{2}$ National Genetic Laboratory, Medical University Sofia, Sofia, Bulgaria

\begin{abstract}
The levels of antibodies to cardiolipin and $\beta 2$-glycoprotein I and polymorphic variants G1691A of Factor V (factor V Leiden, FVL) and G20210A of prothrombin gene (G20210A) were studied in 16 patients with upper-extremity deep vein thrombosis (UEDVT). Most of patients with this syndrome have elevated values of these antibodies. Two of these patients are heterozygous carriers for G20210A and 1 -for FVL. Three patients with UEDVT and systemic lupus erythematosus (SLE) are positive for ANA and two others (one of them with Raynaud syndrome) have border line titre 1:80 for ANA. All 3 patients with SLE are women and the interval between the development of the UEDVT and the onset of SLE was 1-4 years. We would like to suggest that: 1) UEDVT could be the first clinical symptom of Antiphospholipid syndrome, and 2) UEDVT may be the first clinical manifestation of SLE preceding the development of the systemic autoimmune disease by several years.
\end{abstract}

Key words: SLE, antiphospholipid antibodies, upper-extremity deep vein thrombosis.

(Cent Eur J Immunol 2015; 40 (3): 307-310)

\section{Introduction}

Upper-extremity deep vein thrombosis (UEDVT) accounts for approximately $10 \%$ of all cases of deep vein thrombosis (DVT) [1]. Usually the axillar vein and the subclavian vein are involved. According to the mechanism of thrombosis, UEDVT is classified as primary and secondary. Primary UEDVT includes the following disease entities: Paget-Schroetter syndrome (effort thrombosis), thoracic outlet syndrome (TOS) and cases of idiopathic UEDVT. In the $19^{\text {th }}$ century, Sir James Paget (1814-1899) and Leopold von Schroetter (1837-1908) described venous obstruction in the upper extremity, which in 1949, Hughes [2] called Paget-Schroetter syndrome (thrombosis of the axillary - subclavian vein). Paget-Schroetter syndrome is also known as "effort-induced thrombosis", because it is frequently associated with an extreme physical effort [3] in young males who are involved in active sport games, such as long-distance swimming, wrestling, handball, baseball, badminton, rowing, weight lifting or body building exercises. The proposed mechanism of thrombosis in these patients is intimal microtrauma of the vein with subsequent thrombus formation and vascular obstruction [4].

Another form of UEDVT is TOS, associated with thoracic outlet abnormalities and variations, such as abnormalities of the clavicular and cervical ribs, muscle hypertrophy and muscular fascial band, long transverse processes of the cervical spine compressing and damaging the adjacent veins.

Secondary UEVT is observed in oncological patients [5]. The increased risk of DVT in these patients is associated with the following factors: underlying neoplastic disease, advanced age, surgical intervention, hypercoagulability state, chemotherapy, prolonged bed rest, infections, central venous line, etc. Other causes of secondary UEDVT are surgical interventions in this area, pregnancy, and oral contraceptives. Some prothrombotic factors, such as factor V Leiden, prothrombin gene mutation (G20210A), hyperhomocysteinemia, antithrombin III, protein $\mathrm{C}$ and protein $\mathrm{S}$ deficiency have also been stated as causative and/or predisposing factors [6].

\section{Aim of the study}

The aims of our study were:

1. To investigate the serum concentration of the antibodies to cardiolipin (aCL) and to $\beta_{2}$-glycoprotein I (aB-2GPI) in patients with UEDVT.

2. To evaluate the significance of some inherited factors for thromboses in these patients.

3. To search other diseases connected with UEDVT.

Correspondence: Milena K. Nikolova-Vlahova, University Hospital Alexandrovska, 1 G. Sofiiski 1, 1431 Sofia, Bulgaria, e-mail: milena_i_dani@abv.bg 


\section{Material and methods}

Sixteen patients (13 females and 3 males, aged 6-53 years) with UEDVT and 30 controls (13 females and 17 males, aged 30-40 years) were investigated for the presence of aCL and aB-2-GPI (ELISA method, Orgentec-Germany), lupus anticoagulant (LA, using routine aPTT testing method); antinuclear antibodies (ANA, indirect immunofluorescent test on Hep- 2 cells, Euroimmune) and polymorphic variants G1691A of factor $\mathrm{V}$ (Factor V Leiden, FVL) and G20210A of prothrombin genes (G20210A) with polymerase chain reaction (PCR). All antiphospholipid antibodies were investigated twice, at least 2 months apart. Antibodies that were detected twice as being above the normal limits were considered positive. The normal limits of the stated antiphospholipid antibody assays for the Bulgarian population were established investigating 50 healthy volunteers (cut off values: IgG aCL 22 GPL; IgM aCL - 11 MPL; IgG $\beta 2 \mathrm{GPI}$ - $20 \mathrm{U} / \mathrm{ml}$; IgM $\beta 2 \mathrm{GPI}-10 \mathrm{U} / \mathrm{ml}$ ). According to the classification criteria for the diagnosis of APS [7], only aCL > $40 \mathrm{U}$ and $\beta 2 \mathrm{GPI}$ $>99$-th percentile (Table 1) were considered positive.

The diagnosis of UEDVT was made using patients' history, physical evaluation, venography and Doppler-sonography. None of the studied patients had chronic infections, chronic renal or hepatic diseases. None of the female patients was taking oral contraceptives or hormone-replacement therapy, and none was pregnant. None of the investigated patients was an active sportsman, none had prolonged immobilization preceding the development of DVT, none had a malignant disease or central venous line. Several patients had underlying or accompanying diseases: 2 had systemic lupus erythematosus (SLE), 1 - had SLE and thrombosis of vena cava inferior, 2 had pulmonary embolism (PE), 1 had thrombosis of vena cava superior of no detectable cause, 1 had disseminated intravascular coagulation (DIC) of no apparent cause, 1 had Raynaud's syndrome.

\section{Results}

The upper limits of antiphospholipid antibodies were [7]: for IgG aCL - $40 \mathrm{GPL}$; for IgM aCL - $40 \mathrm{MPL}$ [7]; for IgG aB-2-GPI - $20 \mathrm{U}$; for IgM aB-2-GPI - 11 U. In accordance with these threshold values, $9 / 16(56 \%)$ patients had positive IgG aCL; 1/16 (6\%) - positive IgM aCL; 7/16 (44\%) - positive IgG aB-2-GPI and 4/16 (25\%) - positive IgM aB-2-GPI. Overall 5/16 patients (31\%) had no positive autoantibodies. Positive LA (using standard aPTT method) was detected in 4 patients $-25 \%$ (patients $\mathrm{N} 2$, $3,4,6$; in all in association with high antiphospholipid antibodies). Three patients with UEDVT and SLE (NN 1, 6,10 ) had positive ANA and two others (one of them with Raynaud's syndrome) had border-line ANA titer of $1: 80$ (Table 1). Two patients (12\%) were heterozygous carriers of G20210A and $1(6 \%)$ - of FVL (Table 1).

Table 1. Patients with UEDVT

\begin{tabular}{|c|c|c|c|c|c|c|c|c|c|}
\hline $\mathbf{N}$ & Gender & Age & Other diseases & ANA & $\begin{array}{r}\text { IgG } \\
\text { ACL } \\
\end{array}$ & $\begin{array}{r}\text { IgM } \\
\text { ACL } \\
\end{array}$ & $\begin{array}{c}\text { IgG } \\
\text { aB2GPI } \\
\end{array}$ & $\begin{array}{c}\text { IgM } \\
\text { aB2GPI } \\
\end{array}$ & Other \\
\hline 1 & $\mathrm{~F}$ & 33 & SLE, thrombosis of vena cava inferior & $1: 640$ & 30 & 24 & 30 & 12 & \\
\hline 2 & $\mathrm{~F}$ & 30 & DIC & Neg & 54 & 17 & 12 & 12 & \\
\hline 3 & M & 6 & Thrombosis of vena cava superior & Neg & 100 & 7 & 10 & 2 & \\
\hline 4 & $\mathrm{~F}$ & 38 & - & Neg & 100 & 5 & 38 & 4 & \\
\hline 5 & M & 53 & $\mathrm{PE}$ & Neg & 14 & 3 & 10 & 8 & G20210A \\
\hline 6 & $\mathrm{~F}$ & 26 & SLE & $1: 640$ & 18 & 150 & 50 & 20 & G20210A \\
\hline 7 & $\mathrm{~F}$ & 38 & - & $\mathrm{Neg}$ & 36 & 8 & 4 & 2 & \\
\hline 8 & $\mathrm{~F}$ & 24 & - & $\mathrm{Neg}$ & 40 & 2 & 45 & 16 & \\
\hline 9 & $\mathrm{~F}$ & 30 & $\mathrm{PE}$ & $\mathrm{Neg}$ & 56 & 3 & 10 & 8 & \\
\hline 10 & $\mathrm{~F}$ & 40 & SLE & $1: 160$ & 63 & 8 & 80 & 20 & \\
\hline 11 & M & 50 & - & $\mathrm{Neg}$ & 145 & 10 & 53 & 20 & FVL \\
\hline 12 & $\mathrm{~F}$ & 47 & - & $\mathrm{Neg}$ & 120 & 20 & 14 & 5 & \\
\hline 13 & $\mathrm{~F}$ & 42 & - & $\mathrm{Neg}$ & 2 & 24 & 2 & 2 & \\
\hline 14 & $\mathrm{~F}$ & 48 & Raynaud's syndrome & $1: 80$ & 42 & 7 & 44.8 & 5.5 & \\
\hline 15 & $\mathrm{~F}$ & 50 & - & $1: 80$ & 28 & 4 & 14 & 12 & \\
\hline 16 & $\mathrm{~F}$ & 40 & - & $\mathrm{Neg}$ & 3 & 2 & 5 & 6.2 & \\
\hline
\end{tabular}

F-female; $M$ - male; PE - pulmonary thromboembolism; SLE - systemic lupus erythematosus; ANA - antinuclear antibody; aCL - anticardiolipin antibody; aB2GPI-B-2-glycoprotein-I antibody; Neg-negative; G20210A-20210 prothrombin gene mutation; FVL-factor V Leiden mutation 
All 3 patients with SLE were women and the interval between the development of the UEDVT and the onset of SLE was 1 year (N 10), 2 years (N 6) and 4 years (N 1). Subsequently, two of them (N 1 and N 6) developed severe forms of SLE - lupus nephritis, and received high doses of corticosteroids, cyclophosphamide, intravenous immunoglobulins and low molecular weight heparins.

\section{Discussion}

Upper-extremity deep vein thrombosis is much rarer than the DVT of the lower extremities [8]. Along with the etiological factors stated above, several newer prothrombotic conditions have been described, including the antiphospholipid antibodies, FVL and G20210A gene mutation that are known to have a pathogenic role in UEDVT. According to some authors, antiphospholipid antibodies are found in a small proportion of UEDVT patients - between $3.7 \%$ [9] and 7\% [10], whereas others describe a much higher prevalence - $14.8 \%$ [11], 22\% [8] and 26.8\% [12]. In our study, IgG aCL had the highest prevalence $-56 \%$ of the patients, and $6 / 16(37 \%)$ had more than one positive antibody. Overall 11/16 (69\%) patients with UEDVT without clinical data for effort - induced thrombosis, cancer, oral contraceptives, central venous lines or anatomical abnormalities had positive antiphospholipid antibodies.

Antibodies to cardiolipin are found in $17-86 \%$ of the SLE patients and are known to have a pathogenic role in the development of thrombotic complications in these patients [13]. DVT develops 0.5-21.5 years after the first manifestations of SLE, and in $50 \%$ of the SLE patients, these complications develop within the first 2.5 years after the diagnosis [14]. Subclavian vein thrombosis is rare in SLE patients. Brower et al. describe this complication in 2/44 patients in their series [14]. On the other hand, Cervera et al. [15] have found that only $1.9 \%$ of the APS (antiphospholipid syndrome) patients have subclavian vein thrombosis. It is of particular interest in our study that in three SLE patients, subclavian-axillary vein thrombosis was the first manifestation of lupus. All three patients had positive antiphospholipid antibodies and clinical data for the antiphospholipid syndrome. At the diagnosis of UEDVT, the levels of antiphospholipid antibodies were high, but ANA were not investigated. In the study of Chang et al. [16], the first manifestation of SLE in 18/426 (4.2\%) patients was a venous thrombotic incident.

According to Rees et al. [17], the highest prevalence of FVL among Europeans is observed in Greeks - 15\%. In our previous study, we have shown that the prevalence of FVL among healthy Bulgarians is very high $-11.5 \%$ and $9 \%$ of healthy persons are carriers of G20210A gene mutation [18]. The prevalence of heterozygous carrier genotype for FVL among UEDVT patients shows wide variations: $3.7 \%$ [11], 4.9\% [12], 7.4\% [9], 10.6\% [8], 9\% [10], as does the G20210A genotype - from $0 \%[8,12]$ to $10 \%$
[10]. In our study, among idiopathic UEDVT patients, 1/16 $(6 \%)$ was a heterozygous carrier of FVL and 2/16 (12\%) of G20210A. According to Afeltra et al. [19], in Italy $11 \%$ of the SLE patients are heterozygous carriers of G20210A and 3\% - of FVL, whereas in Turkey, Topaloglu et al. [20] have found these mutations in $3.6 \%$ and $12.6 \%$, respectively. Despite the high prevalence of FVL, these authors state that the development of thromboses in these patients is associated with multiple other factors, besides the genetic thrombophilia. In Hungary, Regéczy et al. [21] have found that $13 \%$ of the SLE patients are heterozygous carriers of FVL and in the carriers, the development of thromboses is more frequent. In France, Barcat et al. [22] have found G20210A in $2 \%$ of the SLE patients. In the Netherlands, FVL has been found in $7.9 \%$, and G20210A - in $1.4 \%$ of the SLE patients [14]. According to our previous studies, $5 \%$ of the SLE patients are heterozygous carriers of FVL and this prevalence is lower than in the healthy Bulgarian population [23]. In two patients with UEDVT we found a combination of two prothrombotic factors - high antiphospholipid antibody levels plus G20210A in one SLE patient and high antiphospholipid antibody levels plus FVL in a UEDVT patient without SLE (Table 1).

An interesting overlap in our study was the association between acquired (positive antiphospholipid antibodies) and genetically determined (prothrombin gene mutation and FVL) thrombophilia. This suggests the need for investigation of genetic markers of an increased thrombotic risk in UEDVT patients.

In UEDVT patients, we found different accompanying diseases and conditions, other than SLE, namely thrombosis of vena cava inferior and vena cava superior, disseminated intravascular coagulation (DIC), and pulmonary thromboembolism (PE) as rare embolic complication. One patient had Raynaud's syndrome (Table 1).

The results of our study in a small cohort of idiopathic UEDVT show that the most important prothrombotic factor appears to be the antiphospholipid antibodies. New initiatives for the elucidation of the exact mechanism of thrombosis is APS and for the harmonization and standardization of the methods and are currently taking place around the world [24].

Yet, there remains a certain proportion of patients with idiopathic UEDVT in whom no detectable cause exists [25]. In our cohort, 4 patients $(25 \%)$ had no detectable antiphospholipid antibodies or prothrombotic gene mutation (patients N7, 13, 15, 16 - Table 1).

\section{Conclusions}

Upper-extremity deep vein thrombosis is a disease with uncertain etiology. Most of our patients with this disorder had high levels of aCL and aB-2-GPI antibodies and a part of them subsequently developed other thrombotic incidents. Of great interest is the fact that 3 patients with 
UEDVT subsequently developed SLE. We would like to suggest that: 1) UEDVT could be the first clinical symptom of the antiphospholipid syndrome, and 2) UEDVT may be the first clinical manifestation of SLE preceding the development of the systemic autoimmune disease by several years.

\section{The authors declare no conflict of interest.}

\section{References}

1. Kucher N (2011): Clinical practice. Deep-vein thrombosis of the upper extremities. N Engl J Med 364: 861-869.

2. Zell L, Sommerfeld A, Bucher A (1999): Das Paget - von Schroetter Syndrom: Ein Beitrag zum 100. Todesjahr von Sir James Paget und zur 50-jährigen Namensgebung des Syndroms. DeutschMed Woch 124: 948-951.

3. Drapanas T, Curran WL (1966): Thrombectomy in the treatment of "effort" thrombosis of the axillary and subclavian veins. J Trauma 6: 107.

4. Zell L, Kindermann W, Marschall F, et al. (2001): Paget Schroetter syndrome in sports activities-case study and literature review. Angiology 52: 337-342.

5. Moinat CH, Periard D, Grueber A, et al. (2014): Predictirs of venous thromboembolic events associated with central venous port insertion in cancer patients. J Oncology http// dx.doi.org/10.1155/2014/743181.

6. Joffe HV, Goldhaber SZ (2002): Upper-extremity deep vein thrombosis. Circulation 106: 1874-1880.

7. Miyakis S, Lockshin M, Atsumi T, et al. (2006): International consensus statement on an update of the classification criteria for definite antiphospholipid syndrome. J Thrombosis Haemost 4: 295-306.

8. Heron E, Lozinguez O, Alhenc-Gelas M, et al. (2000): Hypercoagulable states in primary upper-extremity deep vein thrombosis. Arch Int Med 160: 382-386.

9. Prandoni P, Polistena P, Bernardi E, et al. (1997): Upper-extremity deep vein thrombosis risk factors, diagnosis and complications. Arch Int Med 157: 57-62.

10. Martinelli I, Battaglioli T, Bucciarelli P, et al. (2004): Risk factors and recurrence rate of primary deep vein thrombosis of the upper extremities. Circulation 110: 566-576.

11. Ruggeri M, Castaman G, Tosseto A, Rodeghiero F (1997): Low prevalence of thrombophilia coagulation defects in patients with deep vein thrombosis of the upper limbs. Blood Coagul Fibrinol 8: 191-194.

12. Leebeek FWG, Stadhouders NAM, van Stein D, et al. (2001): Hypercoagulability states in upper-extremity deep vein thrombosis. Am J Hematol 67: 15-19.

13. Petri M. Epidemiology of the antiphospholipid antibody syndrome (2000): J Autoimmunity 15: 145-151.

14. Brower J-L P, Bijl M, Veeger NJGM, et al. (2004): The contribution of inherited and acquired thrombophilic defects, alone or combined with antiphospholipid antibodies, to venous and arterial thromboembolism in patients with systemic lupus erythematosus. Blood 104: 143-148.

15. Cervera R, Piette J-M, Font J, et al. (2002): Antiphospholipid syndrome. Clinical and Immunologic Manifestations and Patterns of disease expression in a cohort of 1000 patients. Arthr Rheum 46: 1019-1027.
16. Chang ER, Pineau C, Bernatsky S, et al. (2006): Risk for incident arterial or venous vascular events varies over the course of systemic lupus erythematosus. J Rheumatol 33: 1780-1784.

17. Rees DC, Cox M, Clegg JB (1995): World distribution of factor V Leiden. Lancet: 346: 1133-1134.

18. Boyanovsky B, Russeva M, Ganev V, et al. (2001): Prevalence of factor V Leiden and prothrombin 20210 A variant in Bulgarian patients with pulmonary thromboembolism and deep venous thrombosis. Blood Coagul Fibrinol 12: 639-642.

19. Afeltra A, Vadacca M, Conti L, et al. (2005): Thrombosis in Systemic Lupus Erythematosus: Congenital and Acquired Risk Factors. Arthr \& Rheum (Arthritis Care \& Research) 53: 452-459.

20. Topaloglu R, Akierli C, Bakkaloglu A, et al. (2001): Survey of factor $\mathrm{V}$ leiden and prothrombin gene mutations in systemic lupus erythematosus. Clin Rheumatol 20: 259-261.

21. Regéczy N, Lakos G, Balogh I, et al. (2000): The Leiden mutation of coagulation factor $\mathrm{V}$ in Hungarian SLE patients. Clin Appl Thromb Hemost 6: 41-45.

22. Barcat D, Guèrin V, Ryman A, et al. (2003): Thrombophilia and thrombosis in systemic lupus erythematosus: a casecontrol study. Ann Rheum Dis 62: 1016-1017.

23. Boyanovsky B, Russeva M, Ganev V, et al. (2000): Antiphospholipid syndrome, factor $\mathrm{V}$ Leiden and and activity of protein $\mathrm{C}$ - causes for thromboses in patients with systemic lupus erythematosus. Rheumatology 8: 30-34 (in Bulgarian, English abstract).

24. Bertolaccini ML, Amengual O, Andreoli L, et al. (2014): $14^{\text {th }}$ International congress of antiphospholipid antibodies task force. Report on antiphospholipid syndrome laboratory diagnostics and trends. Autoimmun Rev 13: 917-930.

25. Engelberger RP, Kucher N (2012): Management of deep vein thrombosis of the upper extremity. Circulation 126: 768-773. 